\title{
Chronic (-)-epicatechin improves vascular oxidative and inflammatory status but not hypertension in chronic nitric oxide-deficient rats
}

\author{
Manuel Gómez-Guzmán ${ }^{1}$, Rosario Jiménez ${ }^{1}$, Manuel Sánchez ${ }^{1}$, Miguel Romero ${ }^{1}$, Francisco O’Valle ${ }^{2}$, \\ Rocío Lopez-Sepulveda $^{1}$, Ana María Quintela ${ }^{1}$, Pilar Galindo ${ }^{1}$, María José Zarzuelo ${ }^{1}$, Elvira Bailón ${ }^{1}$, \\ Eva Delpón ${ }^{3}$, Francisco Perez-Vizcaino ${ }^{3,4}$ and Juan Duarte ${ }^{1 *}$ \\ ${ }^{1}$ Department of Pharmacology, School of Pharmacy, University of Granada, 18071 Granada, Spain \\ ${ }^{2}$ Department of Pathology, School of Medicine, Granada, Spain \\ ${ }^{3}$ Department of Pharmacology, School of Medicine, University Complutense of Madrid, Madrid, Spain \\ ${ }^{4}$ Ciber Enfermedades Respiratorias (Ciberes) and Instituto de Investigación Sanitaria del Hospital Clínico San Carlos \\ (IdISSC), Madrid, Spain
}

(Received 1 April 2011 - Revised 21 June 2011 - Accepted 22 June 2011 - First published online 13 September 2011)

\section{Abstract}

The present study analysed the effects of the flavanol (-)-epicatechin in rats after chronic inhibition of NO synthesis with $N^{\mathrm{G}}$-nitro-L-arginine methyl ester (L-NAME), at doses equivalent to those achieved in the studies involving human subjects. Wistar rats were randomly divided into four groups: (1) control-vehicle, (2) L-NAME, (3) L-NAME-epicatechin 2 (L-NAME-Epi 2) and (4) L-NAME-epicatechin 10 (L-NAME-Epi 10). Rats were daily given by oral administration for 4 weeks: vehicle, (-)-epicatechin $2 \mathrm{or} 10 \mathrm{mg} / \mathrm{kg}$. Animals in the L-NAME groups daily received L-NAME $75 \mathrm{mg} / 100 \mathrm{ml}$ in drinking-water. The evolution in systolic blood pressure and heart rate, and morphological and plasma variables, proteinuria, vascular superoxide, reactivity and protein expression at the end of the experiment were analysed. Chronic (-)-epicatechin treatment did not modify the development of hypertension and only weakly affected the endothelial dysfunction induced by L-NAME but prevented the cardiac hypertrophy, the renal parenchyma and vascular lesions and proteinuria, and blunted the prostanoid-mediated enhanced endothelium-dependent vasoconstrictor responses and the cyclo-oxygenase-2 and endothelial NO synthase (eNOS) up-regulation. Furthermore, (-)-epicatechin also increased Akt and eNOS phosphorylation and prevented the L-NAME-induced increase in systemic (plasma malonyldialdehyde and urinary 8 -iso-PGF $2 \alpha$ ) and vascular (dihydroethidium staining, NADPH oxidase activity and $\mathrm{p} 22^{\text {phox }}$ up-regulation) oxidative stress, proinflammatory status (intercellular adhesion molecule-1, IL-1 $\beta$ and TNF $\alpha$ up-regulation) and extracellular-signal-regulated kinase $1 / 2$ phosphorylation. The present study shows for the first time that chronic oral administration of (-)-epicatechin does not improve hypertension but reduced pro-atherogenic pathways such as oxidative stress and proinflammatory status of the vascular wall induced by blockade of NO production.

Key words: (-)-Epicatechin: $N^{G}$-nitro-L-arginine methyl ester: Hypertension: Superoxide: Inflammation

Flavanols, such as (-)-epicatechin, catechin and their oligomers, represent a major class of flavonoids that are commonly present in most higher plants, and with high content in certain foods, such as grapes, tea and cocoa. Several epidemiological investigations and dietary interventions in human subjects using flavanol-containing foods indicate an inverse relationship between flavanol intake and the risk of $\mathrm{CVD}^{(1-5)}$. A very wide range of biological actions of a flavanol-rich diet support these potential cardiovascular protective effects including the improvement of vasodilation ${ }^{(6-8)}$, blood pressure $^{(9,10)}$, insulin resistance ${ }^{(11)}$, the attenuation of platelet reactivity ${ }^{(12)}$, and the improvement of immune responses and antioxidant defence system ${ }^{(13)}$. However, little is known about the molecular mechanisms of flavanol-mediated bioactivities in both humans and animals. The reasons for these shortcomings are, at least in part, based on the fact that food matrices contain a multitude of phytochemical constituents, of which an unknown number may exert physiological effects. The effect of high-flavanol cocoa was mimicked by oral intake of pure (-)-epicatechin isolated from cocoa, and the maximum effect on endothelial function coincided with the peak of the plasma level of $(-)$-epicatechin metabolites ${ }^{(8)}$.

Abbreviations: COX, cyclo-oxygenase; eNOS, endothelial nitric oxide synthase; ERK1/2, extracellular-signal-regulated kinase 1/2; ICAM-1, intercellular adhesion molecule-1; iso-PGF $2 \alpha$, 8-iso-PGF $2 \alpha$; L-NAME, $N^{\mathrm{G}}$-nitro-L-arginine methyl ester; MDA, malondialdehyde; NOS, nitric oxide synthase; ROS, reactive oxygen species; $\mathrm{SBP}$, systolic blood pressure.

*Corresponding author: J. Duarte, fax +34 958248964, email jmduarte@ugr.es 
(-)-Epicatechin controls vascular tone in vitro inducing endothelium-dependent NO-mediated vasodilation ${ }^{(14,15)}$ and improving endothelial dysfunction in diabetes ${ }^{(16)}$. (-)-Epicatechin in vitro induced activation of endothelial NO synthase (eNOS) through two mechanisms: (i) eNOS phosphorylation by the participation of the phosphatidylinositol 3-kinase pathway and (ii) activation of the $\mathrm{Ca}^{2+} /$ calmodulin-dependent kinase II pathway ${ }^{(17)}$. Moreover, (-)-epicatechin elevates NO in endothelial cells via inhibition of the main superoxide generating system NADPH oxidase ${ }^{(18)}$. Furthermore, a number of endothelial cell-protective actions of (-)-epicatechin have been described, including protection against cytotoxicity, oxidative stress-related modifications of proteins and DNA, and proteasomal breakdown of eNOS ${ }^{(18)}$.

We hypothesised that chronic (-)-epicatechin treatment might prevent the development of pathological changes associated with hypertension independently on its protective effects on NO. Therefore, we analysed the effects of (-)-epicatechin, at doses equivalent to those achieved in the human diet, in a model of chronic inhibition of NO synthase (NOS) using the NOS inhibitor $N^{\mathrm{G}}$-nitro-L-arginine methyl ester (L-NAME). This model develops arterial hypertension and is associated with a vascular pro-oxidant, pro-atherogenic and proinflammatory phenotype ${ }^{(19,20)}$.

\section{Methods}

\section{Experimental protocols}

The experimental protocol followed the European Union guidelines for animal care and protection. Male Wistar rats (315-400g) were used in the study after an adaptation period of 2 weeks for vehicle administration and blood pressure measurements. Rats were randomly assigned to four different treatment groups for 4 weeks: (a) vehicle (control, $1 \mathrm{ml}$ of $1 \%$ methylcellulose once daily, $n$ 8), (b) vehicle plus L-NAME $(75 \mathrm{mg} / 100 \mathrm{ml}$ in drinking-water, approximately $75 \mathrm{mg} / \mathrm{kg}$ per d, $n$ 10), (c) (-)-epicatechin $(2 \mathrm{mg} / \mathrm{kg}$ inoculation by oral administration, mixed in $1 \mathrm{ml}$ of $1 \%$ methylcellulose once daily, $n$ 10) plus L-NAME and (d) (-)epicatechin $(10 \mathrm{mg} / \mathrm{kg}$ oral inoculation, mixed in $1 \mathrm{ml}$ of $1 \%$ methylcellulose once daily, $n$ 10) plus L-NAME. The administration doses of (-)-epicatechin in this study correspond to approximately $120-600 \mathrm{mg}$ in humans (at a body weight of $60 \mathrm{~kg}$ ), which are in the range than can be achieved in the human diet (e.g. flavanol content in dark chocolate used in intervention studies) and approximately two to ten times the average daily catechin intake in humans. The treatment with (-)-epicatechin was stopped $2 \mathrm{~d}$ before the end of the study in order to analyse the long-term effects of (-)-epicatechin without the involvement of the effects of acute administration; and on the last day, the animals were placed in metabolic cages to collect urine for $24 \mathrm{~h}$.

\section{Blood pressure measurements}

Systolic blood pressure (SBP) was measured every week in conscious rats by tail-cuff plethysmography ${ }^{(21)}$. At least seven determinations were made in every session and the mean of the lowest three values within $5 \mathrm{mmHg}$ was taken as the SBP.

\section{Plasma and urinary determinations}

Proteinuria was determined according to the Bradford method and the results were expressed as $\mathrm{mg}$ of protein excreted per $100 \mathrm{~g}$ of rat during $24 \mathrm{~h}$. Plasma levels of malondialdehyde (MDA) were assessed following the method described by Esterbauer \& Cheeseman ${ }^{(22)}$. Total 8-iso-PGF $2 \alpha$ (iso- PGF $_{2 \alpha}$ ) and TNF $\alpha$ were measured by an enzyme-immunoassay kit (Cayman Chemical and Diaclone, Inc., Besancon, France, specific for rat $\mathrm{TNF} \alpha$, respectively).

\section{Histological techniques}

Formaldehyde-fixed, paraffin-embedded longitudinal kidney Wistar rat sections in the sagittal plane were stained with haematoxylin and eosin, and periodic acid-Schiff stain. The extent of vascular injury (stenosis, hyaline arteriopathy and myointimal proliferative hyperplasia) was assessed by examining profiles of arteries and arterioles in a single kidney section and counting the number of vessels affected. The presence of glomerular lesions (glomerulosclerosis and capsular fibrosis) was evaluated in at least 200 glomeruli. Tubular atrophy and tubular casts were also evaluated. The morphological study was done in blinded fashion on $4-\mu \mathrm{m}$ sections with light microscopy, using the most appropriate stain for each lesion. The values were expressed as the percentage of rats with lesions in each group, and the severity of lesions was calculated semiquantitatively using a 0 -to-3 scale ( 0 , absence; 1 , mild ( $<10 \%$ of vessel, tubules or glomeruli involved); 2 , moderate $(10-25 \%)$; 3, severe $(>25 \%))$.

\section{Vascular contractility in vitro}

Descending thoracic aortic rings $(3 \mathrm{~mm})$ and the fourth branch of the mesenteric artery $(1.7-2 \mathrm{~mm})$ were dissected from animals and were mounted in organ chambers and in a wire myograph (model 610M; Danish Myo Technology, Aarhus, Denmark), respectively, filled with Krebs solution as previously described ${ }^{(23)}$. In endothelium-denuded aorta, the concentration-relaxation response curves to nitroprusside $\left(10^{-9}-10^{-5} \mathrm{M}\right)$ were performed in rings pre-contracted by $10^{-6} \mathrm{M}$-phenylephrine. The relaxant responses to acetylcholine were also studied in both intact-small mesenteric artery and -aorta pre-contracted by phenylephrine $(5 \mu \mathrm{M}$ in mesenteric artery and 1 or $0 \cdot 1 \mu \mathrm{M}$ in control or L-NAME-treated aortic rings, respectively, to obtain a similar level of precontraction). Contractions evoked by acetylcholine were tested in aortic rings with endothelium incubated for $30 \mathrm{~min}$ with L-NAME $\left(10^{-4} \mathrm{M}\right)$; responses were expressed as a percentage of a previous response to $80 \mathrm{~mm}-\mathrm{KCl}$.

\section{In situ detection of vascular superoxide anion levels}

Unfixed thoracic aortic rings were cryopreserved (PBS $0 \cdot 1 \mathrm{~mol} / 1$, plus $30 \%$ sucrose for $1-2 \mathrm{~h}$ ), included in optimum 
cutting temperature, frozen $\left(-80^{\circ} \mathrm{C}\right)$, and $10 \mu \mathrm{m}$ cross-sections were obtained in a cryostat. Sections were incubated for $30 \mathrm{~min}$ in HEPES-buffered solution containing dihydroethidium $\left(10^{-5} \mathrm{M}\right)$, counterstained with the nuclear stain 4'-6-diamidino-2-phenylindole and photographed on a fluorescence microscope. Superoxide anion $\left(\mathrm{O}_{2}^{-}\right)$level was estimated from the ratio of ethidium:4'-6-diamidino-2-phenylindole fluorescence ${ }^{(24)}$. In preliminary experiments, dihydroethidium fluorescence was almost abolished by the $\mathrm{O}_{2}^{-}$scavenger tiron, indicating the specificity of this reaction.

\section{NADPH oxidase activity}

The lucigenin-enhanced chemiluminescence assay was used to determine NADPH oxidase activity in intact aortic rings, as previously described ${ }^{(25)}$. Aortic production of $\mathrm{O}_{2}^{-}$was stimulated by the addition of NADPH $(100 \mu \mathrm{M})$. Rings were then placed with or without NADPH, and lucigenin was injected automatically at a final concentration of $5 \mu \mathrm{m}$ to avoid known artifacts when used at higher concentrations in a scintillation counter (Lumat LB 9507; Berthold, Germany). Vessels were then dried, and dry weight was determined. NADPH oxidase activity is expressed as relative luminescence units/min per mg dry aortic tissue.

\section{Western blotting analysis}

Aortic homogenates were run on SDS-PAGE. Proteins were transferred to polyvinylidene difluoride membranes, incubated with primary monoclonal mouse anti-eNOS (Cell Signaling Technology, Danvers, MA, USA), anti-phospho-eNOS (Ser-1177) (Cell Signaling Technology), rabbit polyclonal anti-cyclo-oxygenase 2 (COX-2; Santa Cruz Biotechnology, Santa Cruz, CA, USA), rabbit anti-phospho-Akt-Ser-473, rabbit anti-Akt, rabbit anti-extracellular-signal-regulated kinase $1 / 2$ (ERK1/2; Cell Signaling Technology) or mouse anti-phosphoERK1/2-Thr183 and Tyr185 (Sigma-Aldrich, Alcobendas, Spain), polyclonal goat anti-p $22^{\text {phox }}$, or polyclonal rabbit anti-p $47^{\text {phox }}$ (Santa Cruz Biotechnology) antibodies overnight and with the correspondent secondary peroxidase conjugated antibodies. Antibody binding was detected by an enhanced chemiluminescence system (Amersham Pharmacia Biotech, Amersham, UK) and densitometric analysis was performed using Scion ImageRelease Beta 4.02 software (Scion Corporation, Frederick, MD, USA). Samples were re-probed for expression of smooth muscle $\alpha$-actin or ERK1/2. Protein abundance: $\alpha$-actin ratio or phospho-Akt/Akt, phospho-ERK1/2/ERK1/2 and phosphoeNOS/eNOS were calculated and data are expressed as a percentage of the values in control aorta from the same gel.

\section{$R T-P C R$ analysis}

For RT-PCR analysis, total RNA was extracted and converted to complementary DNA by standard methods. PCR was performed with a Techne Techgene thermocycler (Techne, Cambridge, UK). Initial denaturation was done at $95^{\circ} \mathrm{C}$ for $3 \mathrm{~min}$ and followed by thirty-two to thirty-five (thirty-two for p $22^{\text {phox }}$, eNOS, intercellular adhesion molecule-1 (ICAM-1),
TNF $\alpha$ and IL-1 $\beta$, and thirty-five for $\mathrm{p} 47^{\mathrm{phox}}$ ) cycles of amplification. Each cycle consisted of 1 min of denaturation at $94^{\circ} \mathrm{C}, 45 \mathrm{~s}$ of annealing at $55^{\circ} \mathrm{C}$ for $\mathrm{p} 22^{\text {phox }}$, ICAM- 1 and IL- $1 \beta$, $57^{\circ} \mathrm{C}$ for $\mathrm{TNF} \alpha$ and $58^{\circ} \mathrm{C}$ for eNOS and $57^{\circ} \mathrm{C}$ for $\mathrm{p} 47^{\text {phox }}$, and $1 \mathrm{~min}$ for enzymatic primer extension at $72^{\circ} \mathrm{C}$. After the final cycle, the temperature was held at $72^{\circ} \mathrm{C}$ for $10 \mathrm{~min}$ to allow reannealing of amplified products. RT-PCR products were then size-fractionated through a $1 \%$ agarose gel, and the bands were visualised with ethidium bromide and quantified by densitometric analysis performed on the scanned images using Scion Image-Release Beta 4.02 software (Scion Corporation, Frederick, MD, USA; http://www.scioncorp.com). The sequences for primers were as follows: $47^{\text {phox }}$ (100 bp) sense, 5'-ATGACAGCCAGGTGAAGAAGC- $3^{\prime}$ and antisense, 5'-CGATAGGTCTGAAGGCTGATGG-3'; $22^{\text {phox }}$ (220 bp) sense 5'-GCGGTGTGGACAGAAGTACC- $3^{\prime}$ and antisense, 5'-CTTGGGTTTAGGCTCAATGG- $3^{\prime}$; eNOS (161 bp) sense $5^{\prime}$-ATGGATGAGCCAACTCAAGG- $3^{\prime}$ and antisense, 5'-TGTCGTGTAATCGGTCTTGC-3'; ICAM-1 (386 bp) sense $5^{\prime}$-AGGTATCCATCCATCCCACA- $3^{\prime}$ and antisense, 5'-AGTGTCTCATTGCCACGGAG-3'; TNF $\alpha$ (468bp) sense 5'-ATGTGGAACTGGCAGAGGAG- $3^{\prime}$ and antisense, $5^{\prime}$ - GGCCATGGAACTGATGAGAG-3'; IL-1 $\beta$ ( 497 bp) sense 5'- AGGCAGTGTCACTCATTGTG-3' and antisense, 5'-GGAGAGCTTTCAGCTCACAT- 3 '. Glyceraldehyde 3-phosphate dehydrogenase was used as an internal control for the co-amplification. The signals were expressed relative to the intensity of glyceraldehyde 3-phosphate dehydrogenase in each sample.

\section{Drugs}

All drugs and chemicals were obtained from Sigma (Alcobendas, Spain), and dissolved in distilled deionised water, except for (-)-epicatechin, which was mixed with $1 \%$ methylcellulose.

\section{Statistical analysis}

Results are expressed as means with their standard errors. Statistically significant differences were calculated by one-way ANOVA analysis followed by Bonferroni's post boc test. $P<0.05$ was considered statistically significant. Renal lesion severity was analysed by the Mann-Whitney $U$ test.

\section{Results}

Effects in blood pressure and left ventricular and kidney weight indices

Rats receiving chronic L-NAME treatment showed a progressive increase in SBP and decrease in heart rate (Fig. 1), which were already significant after the first week. Concomitant treatment with $(-)$-epicatechin $(2$ and $10 \mathrm{mg} / \mathrm{kg}) \mathrm{did}$ not prevent the changes in either SBP or heart rate. At the end of the study period, L-NAME significantly increased the heart (13\%) and left ventricular (22\%) weight indices as compared to the control group. In rats receiving L-NAME plus (-)-epicatechin at $10 \mathrm{mg} / \mathrm{kg}$, these parameters were significantly reduced as compared to the L-NAME group (Table 1). 

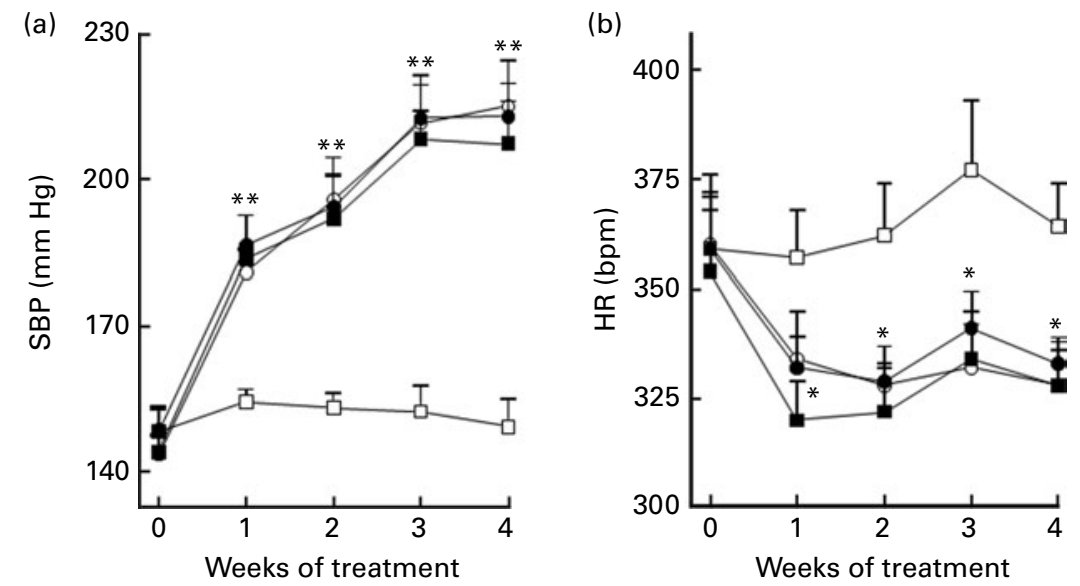

Fig. 1. Effects in (a) systolic blood pressure (SBP) and (b) heart rate (HR) as measured by tail-cuff plethysmography in control ( $\square$ ), $N^{G}$-nitro-L-arginine methyl ester (L-NAME, 口), L-NAME $+2 \mathrm{mg} / \mathrm{kg}$ epicatechin (Epi 2, O) and L-NAME $+10 \mathrm{mg} / \mathrm{kg}$ epicatechin (Epi 10, $\bullet$ ) groups. Values are means, with their standard errors represented by vertical bars. Mean values were significantly different between L-NAME and control group: ${ }^{\star} P<0.05,{ }^{\star \star} P<0.01$. bpm, beats per minute.

\section{Effects in renal histology and proteinuria}

L-NAME induced moderate/severe renal injury which affected $40 \%$ of the animals. Hyaline and proliferative (myointimal proliferative hyperplasia) arteriopathy were the main and most intense lesions associated with thickening of the vascular wall and decrease of lumen (Fig. 2(a) and Table S1, supplementary material for this article can be found at http://www.journals.cambridge.org/bjn). The intensity, number and size of the vessel affected with hyaline arteriopathy and myointimal proliferative hyperplasia were significantly decreased by treatment with (-)-epicatechin $10 \mathrm{mg} / \mathrm{kg}$. Glomerular and tubulointerstitial lesions were not present, except in L-NAME and L-NAME-plus epicatechin 2 groups which present only weak and scattered tubular cast and tubular atrophy. Proteinuria was markedly increased in the L-NAME group and this effect was reduced only by $10 \mathrm{mg} / \mathrm{kg}$ (-)-epicatechin (Fig. 2(b)).

\section{Effects in systemic reactive oxygen species}

Plasma MDA level, a marker of lipid peroxidation induced by reactive oxygen species (ROS), in L-NAME-treated animals was increased (89\%) as compared to the control group. In L-NAME plus (-)-epicatechin-treated rats, MDA concentration was reduced only in rats treated with $10 \mathrm{mg} / \mathrm{kg}(-)$-epicatechin
(Fig. 3(a)). The $24 \mathrm{~h}$ urinary iso-PGF ${ }_{2 \alpha}$ excretion, a more specific marker of oxidative stress, was also increased in the L-NAME group. In both groups of $(-)$-epicatechin-treated LNAME rats, iso-PGF $2 \alpha$ excretion showed similar values to those of control rats (Fig. 3(b)).

\section{Effects in vascular NO pathway}

Aortae from L-NAME-treated rats showed strongly reduced endothelium-dependent vasodilator responses to acetylcholine (Fig. 4(a)). The aortae from L-NAME plus (-)-epicatechin at $10 \mathrm{mg} / \mathrm{kg}$ treated animals showed a small increase in the vasodilation induced by acetylcholine as compared to animals from the L-NAME group. In aortic rings, no differences were observed among groups in the endothelium-independent vasodilator responses to the NO donor sodium nitroprusside (Fig. 4(b)). In intact-small mesenteric arteries, acetylcholine elicited concentration-dependent relaxations that were inhibited by chronic L-NAME treatment (Fig. 4(c)). (-)-Epicatechin $2 \mathrm{mg} / \mathrm{kg}$ did not prevent this effect of L-NAME and the dose of $10 \mathrm{mg} / \mathrm{kg}$ marginally but significantly increased the relaxant response induced by the highest concentration of acetylcholine.

eNOS mRNA in the aorta from the L-NAME group was increased as compared to the control group and both

Table 1. Body weight (BW) and cardiac and renal indices (Mean values with their standard errors)

\begin{tabular}{|c|c|c|c|c|c|c|c|c|c|c|c|c|c|c|c|}
\hline \multirow[b]{2}{*}{ Group } & \multirow[b]{2}{*}{$n$} & \multicolumn{2}{|c|}{ BW (g) } & \multicolumn{2}{|c|}{ HW (mg) } & \multicolumn{2}{|c|}{ LVW (mg) } & \multicolumn{2}{|c|}{$\mathrm{KW}$ (mg) } & \multicolumn{2}{|c|}{ HW:BW ratio } & \multicolumn{2}{|c|}{ LVW:BW ratio } & \multicolumn{2}{|c|}{$\mathrm{KW}: \mathrm{BW}$ ratio } \\
\hline & & Mean & SEM & Mean & SEM & Mean & SEM & Mean & SEM & Mean & SEM & Mean & SEM & Mean & SEM \\
\hline Control & 8 & 384 & 11 & 972 & 46 & 670 & 27 & 1030 & 39 & 2.52 & 0.07 & 1.74 & 0.02 & $2 \cdot 68$ & 0.07 \\
\hline L-NAME & 10 & 363 & 11 & 1041 & 47 & $770^{\star}$ & 31 & 953 & 37 & $2 \cdot 86^{\star \star}$ & 0.07 & $2 \cdot 12^{\star \star}$ & 0.06 & $2 \cdot 62$ & 0.14 \\
\hline L-NAME + epi 2 & 10 & 339 & 12 & 944 & 39 & 691 & 31 & 864 & 42 & $2 \cdot 79$ & 0.07 & 2.04 & 0.07 & 2.55 & 0.08 \\
\hline L-NAME + epi 10 & 10 & 355 & 13 & 951 & 45 & 698 & 30 & 936 & 42 & $2 \cdot 67 \dagger$ & 0.07 & $1.96 \dagger$ & 0.04 & 2.63 & 0.08 \\
\hline
\end{tabular}

$\mathrm{HW}$, heart weight; LVW, left ventricular weight; KW, kidney weight; L-NAME, $N^{\mathrm{G}}$-nitro-L-arginine methyl ester; epi, epicatechin

Mean values were significantly different from those of the control group: ${ }^{*} P<0.01,{ }^{* *} P<0.01$.

$\dagger$ Mean values were significantly different from those of the L-NAME group $(P<0.05)$. 
(a) (i)
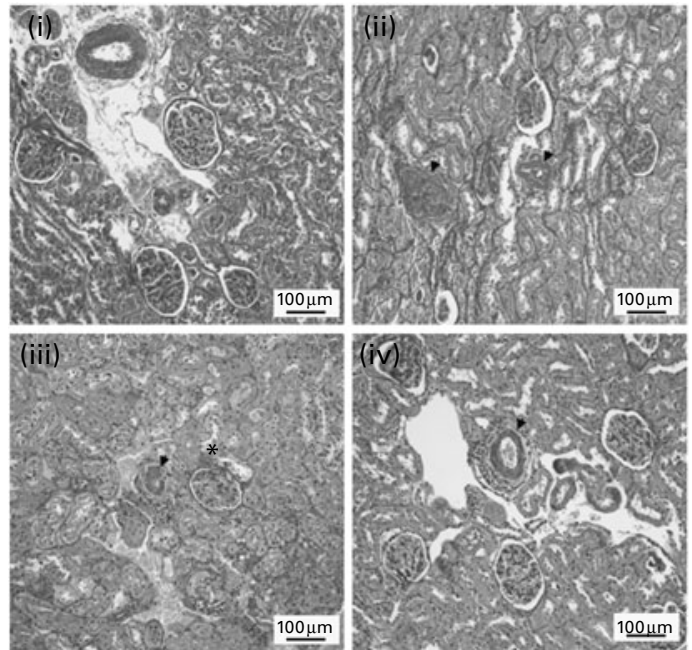

(b)

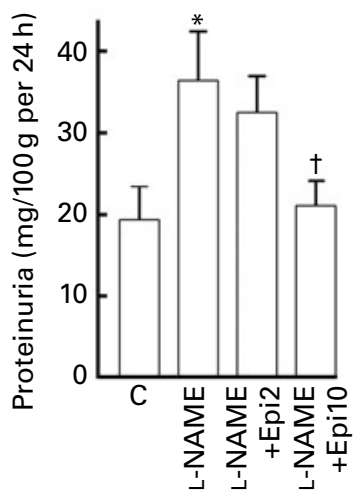

Fig. 2. Effects of epicatechin (Epi) in renal injury. (a) Renal parenchyma in $N^{G}$-nitro-L-arginine methyl ester (L-NAME) hypertension model. (i) Absence of vascular, glomerular or tubulointerstitical lesions in control (C) group; (ii) vessels with hyaline arteriopathy and myointimal proliferative hyperplasia (arrows) in L-NAME group; (iii) moderate/severe hyaline arteriopathy in afferent arteriole of glomerulus (*) and interlobular arteria with lumen reduction (arrow) in L-NAME + Epi 2 group; (iv) circumferential hyalin arteriopathy without lumen reduction in L-NAME + Epi 10 group (arrow). (b) Proteinuria in all experimental groups. Values are means, with their standard errors represented by vertical bars. ${ }^{*}$ Mean values were significantly different between the L-NAME and $C$ groups $(P<0.05)$. $\dagger$ Mean values were significantly different between the L-NAME-Epi and L-NAME groups $(P<0.05)$.

groups of rats treated with L-NAME plus (-)-epicatechin showed reduced expression of eNOS as compared to the L-NAME group alone (Fig. 5(b)). We also observed that (-)-epicatechin treatment significantly increased eNOS phosphorylation at Ser-1177, as compared to the control and the L-NAME groups (Fig. 5(c)).

\section{Effects on vascular cyclo-oxygenase pathway}

Aortae from L-NAME-treated rats showed strongly increased endothelium-dependent vasoconstrictor responses to acetylcholine (Fig. 6(a)), which are related to COX-derived metabolites. This effect was accompanied by an increased COX-2 mRNA (Fig. 6(b)) and protein expression (Fig. 6(c)). The aortae from L-NAME plus (-)-epicatechin at $10 \mathrm{mg} / \mathrm{kg}$ treated animals showed reduced vasoconstrictor responses to acetylcholine and COX-2 expression, as compared to the L-NAME group.

\section{Effects in vascular superoxide anion production and NADPH oxidase pathway}

To characterise and localise vascular ROS production, sections of aorta were incubated with dihydroethidium which is
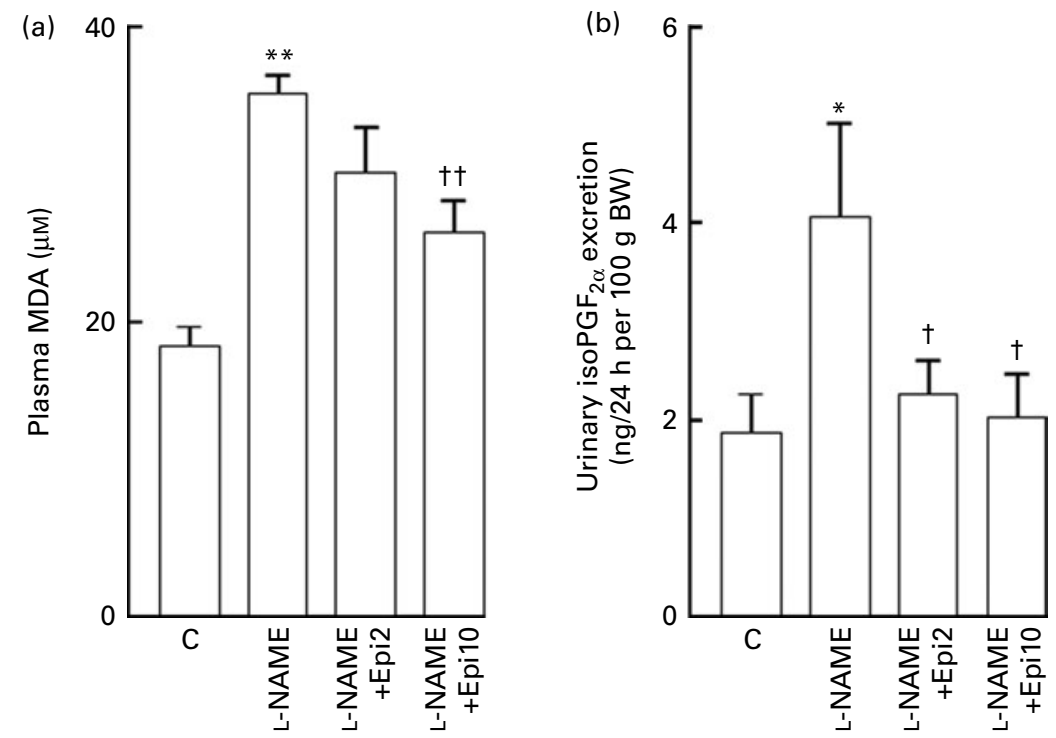

Fig. 3. Effects of epicatechin (Epi) in systemic oxidative markers. (a) Plasma malondialdehyde (MDA) content and (b) urinary excretion of 8-iso-PGF ${ }_{2 \alpha}$ in contro (C), $N^{G}$-nitro-L-arginine methyl ester (L-NAME), L-NAME $+2 \mathrm{mg} / \mathrm{kg}$ Epi (Epi 2) and L-NAME $+10 \mathrm{mg} / \mathrm{kg}$ Epi (Epi 10) groups. Values are means, with their standard errors represented by vertical bars. Mean values were significantly different between the L-NAME and $C$ groups: ${ }^{\star} P<0.05$, ${ }^{\star \star} P<0.01$. Mean values were significantly different between the L-NAME-Epi and L-NAME groups: $\uparrow P<0.05 ; \dagger \uparrow P<0.01$. BW, body weight. 

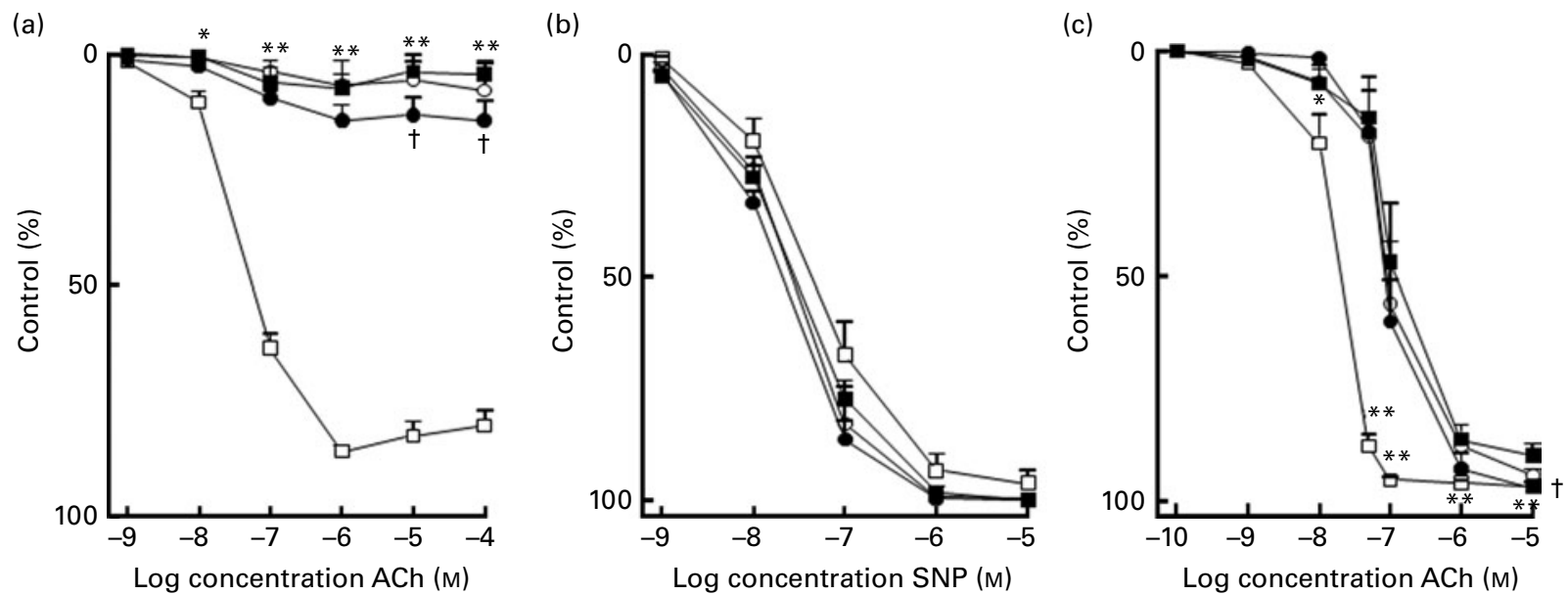

Fig. 4. Effects of epicatechin (Epi) on endothelial function. Vascular relaxant responses induced by (a) acetylcholine (ACh) and (b) sodium nitroprusside (SNP) in aortae pre-contracted by $1 \mu \mathrm{M}$ phenylephrine (Phe), and by ACh in small mesenteric arteries contracted by $5 \mu \mathrm{M}$-Phe (c) in aortae from control ( $\square$ ), $N^{G}$-nitro-L-arginine methyl ester (L-NAME, 口), L-NAME + $2 \mathrm{mg} / \mathrm{kg}$ Epi (Epi 2, O) and L-NAME + $10 \mathrm{mg} / \mathrm{kg}$ Epi (Epi 10, $\bullet$ ) groups. Values are means, with their standard errors represented by vertical bars. Mean values were significantly different between the L-NAME and control groups: ${ }^{*} P<0 \cdot 05,{ }^{* \star} P<0.01$. $†$ Mean values were significantly different between the L-NAME-Epi and L-NAME groups $(P<0.05)$.

oxidised by $\mathrm{O}_{2}^{-}$to yield the red fluorescent DNA stain ethidium. Fluorescence was almost suppressed by the $\mathrm{O}_{2}^{-}$scavenger tiron $(10 \mathrm{mM}$, data not shown). Rings from L-NAME rats showed marked increased staining in adventitial, medial and endothelial cells (Fig. 7(a)). Red fluorescence, normalised to the blue fluorescence of the nuclear stain 4'-6-diamidino-2phenylindole, was reduced after $10 \mathrm{mg} / \mathrm{kg}$ (-)-epicatechin treatment (Fig. 7(b)).

$\mathrm{NADPH}$ increases lucigenin luminescence in normal aortic rings, which was almost abolished by the flavoprotein inhibitor diphenyliodonium (10 $\mu \mathrm{M}$, not shown), showing that external NADPH increased NADPH oxidase activity in vascular tissue. NADPH oxidase activity was increased in aortic rings from L-NAME rats as compared to control rats. Chronic treatments with (-)-epicatechin, at both doses, abolished this increased NADPH oxidase activity in L-NAME-treated rats
(Fig. 8(a)). Significant p22 $2^{\text {phox }}$ mRNA (Fig. 8(b)) and protein (Fig. 8(c)) up-regulation, without changes in $\mathrm{p} 47^{\text {phox }}$ (Fig. 8(d) and (e)), was observed in aortic tissue from LNAME rats. (-)-Epicatechin treatment, at both doses, inhibited the $\mathrm{p} 22^{\mathrm{phox}}$ gene overexpression in L-NAME-treated animals.

\section{Effects on inflammatory status}

The mRNA expression of ICAM-1 (Fig. 9(a)) and proinflammatory cytokines IL-1 $\beta$ (Fig. 9(b)), or TNF $\alpha$ (Fig. 9(c)) in aortic homogenates was higher in aortae from L-NAME groups as compared to control rats. Plasma TNF $\alpha$ levels (Fig. 9(d)) were also increased in L-NAME-treated rats. (-)-Epicatechin treatment, at both doses, significantly down-regulated these genes, and reduced plasma levels of TNF $\alpha$. (a)
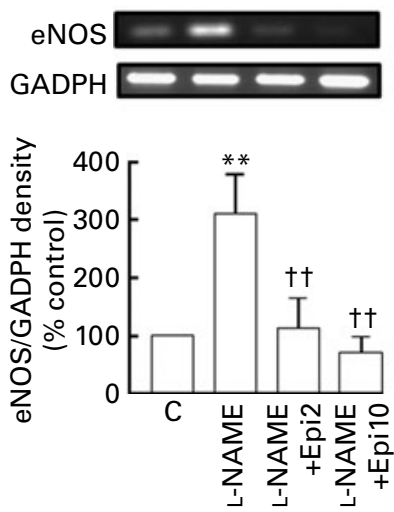

(b)
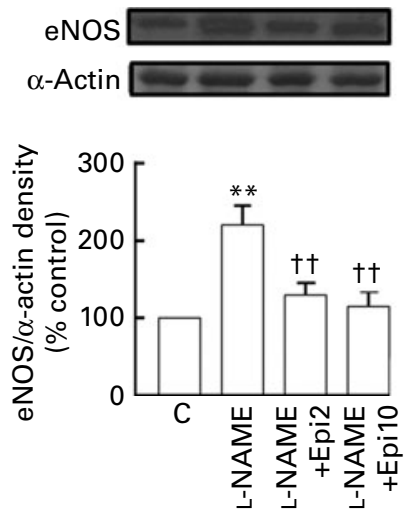

(c)
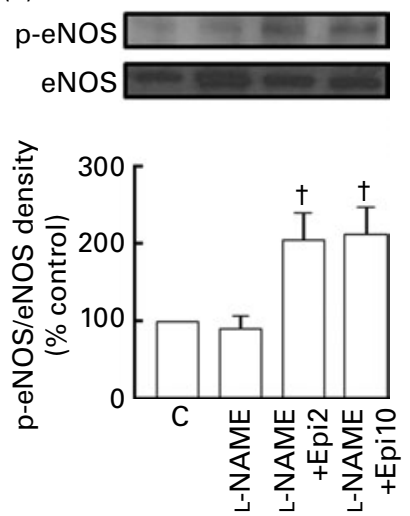

Fig. 5. Effects of epicatechin (Epi) on endothelial nitric oxide synthase (eNOS). Gene expression of eNOS by (a) RT-PCR, (b) Western blot and (c) Ser-1177phospho-eNOS (p-eNOS) in control (C), $N^{G}$-nitro-L-arginine methyl ester (L-NAME), L-NAME $+2 \mathrm{mg} / \mathrm{kg}$ Epi (Epi 2) and L-NAME $+10 \mathrm{mg} / \mathrm{kg}$ Epi (Epi 10) groups. Panels show representative bands and histograms represent densitometric values normalised to the corresponding RT-PCR products of (a) glyceraldehyde 3-phosphate dehydrogenase (GADPH) or normalised to the corresponding (b) $\alpha$-actin or (c) eNOS. Values are means, with their standard errors represented by vertical bars $(n 3-5)$. ${ }^{* *}$ Mean values were significantly different between the L-NAME and $\mathrm{C}$ groups $(P<0.01)$. Mean values were significantly different between the L-NAME-Epi and L-NAME groups: $\dagger P<0.05 ; \dagger \uparrow P<0.01$. 
(a)

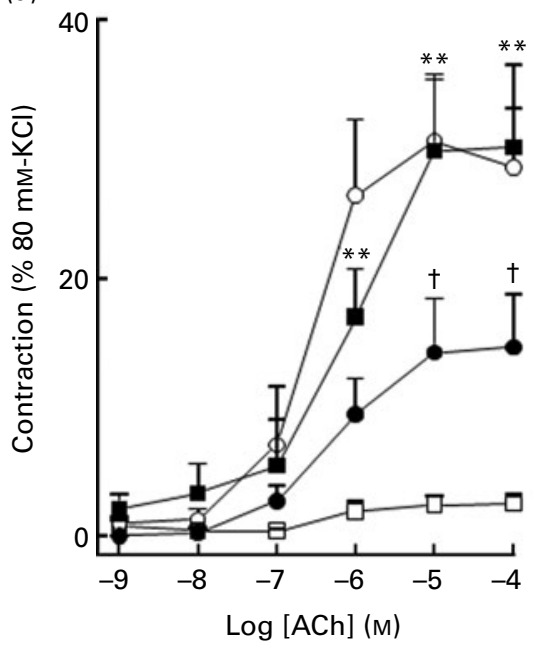

(b)
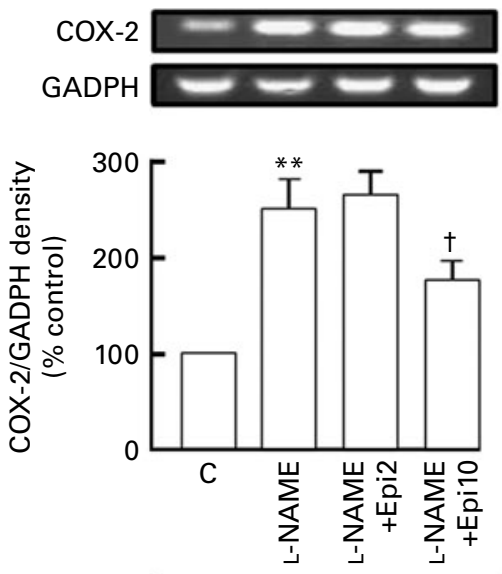

(c)
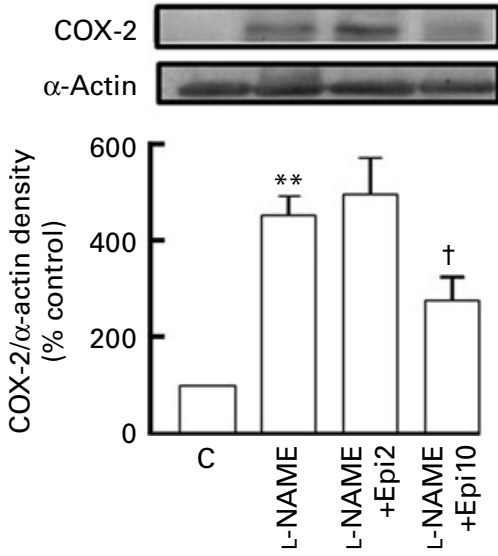

Fig. 6. Effects of epicatechin (Epi) on the cyclo-oxygenase (COX) pathway. (a) Endothelium-dependent contractions induced by acetylcholine (ACh) in aortae from control (C), $N^{\mathrm{G}}$-nitro-L-arginine methyl ester (L-NAME), L-NAME $+2 \mathrm{mg} / \mathrm{kg}$ Epi (Epi 2) and L-NAME $+10 \mathrm{mg} / \mathrm{kg}$ Epi (Epi 10) groups. ACh-induced contractions were induced in arteries treated with L-NAME $\left(10^{-4} \mathrm{M}\right)$ in the organ bath and expressed as a percentage of the response to $80 \mathrm{mM}-\mathrm{KCl}$. Expression of (b) COX-2 at the level of mRNA by RT-PCR and (c) protein by Western blot in all experimental groups. Panels show representative bands and histograms represent densitometric values normalised to the corresponding RT-PCR products of (b) glyceraldehyde 3-phosphate dehydrogenase (GADPH) or normalised to the corresponding (c) $\alpha$-actin. Values are means, with their standard errors represented by vertical bars $(n 3-5)$. ${ }^{* *}$ Mean values were significantly different between the L-NAME and $\mathrm{C}$ groups $(P<0.01)$. † Mean values were significantly different between the L-NAME-Epi and L-NAME groups $(P<0.05)$.

Effects on vascular extracellular-signal-regulated kinase 1/ 2 and Akt pathways

The expression of phospho-protein kinase B (Akt) (Fig. 10(a)) and phospho-ERK1/2 (Fig. 10(b)) proteins was increased in aorta by L-NAME. Chronic (-)-epicatechin treatment increased Akt phosphorylation and reduced ERK1/2 phosphorylation in rats with chronic NO-deficient hypertension.

\section{Discussion}

Administration of L-NAME in drinking-water induces a progressive increase in arterial blood pressure which is attributed to a reduced synthesis of the vasodilator $\mathrm{NO}$ and has been widely used as a model of chronic hypertension ${ }^{(20)}$. The present study shows for the first time that a single oral daily dose of (-)-epicatechin (2 or $10 \mathrm{mg} / \mathrm{kg}$ ) partially or fully prevented most of the effects induced by L-NAME (Fig. 11) such as (a) increases in the left ventricular hypertrophy, (b) proteinuria, (c) renal histological lesions, (d) increased plasma MDA concentrations and urinary iso- $\mathrm{PGF}_{2 \alpha}$ excretion, (e) increased endothelium-dependent contraction and COX-2 overexpression, (f) increased vascular production of $\mathrm{O}_{2}^{-}$and NADPH oxidase activity and $(\mathrm{g})$ increased vascular inflammatory status. In most cases, these effects were dosedependent. However, it did not inhibit the development of hypertension and had only minor effects on the impaired endothelium- and NO-dependent relaxation. Interestingly, changes in several end-points were not dependent on the presence of (-)-epicatechin in blood, since they were obtained $48 \mathrm{~h}$ after the deprivation of the flavanol, indicating that it alters the course of the disease via permanent structural changes and/or alteration of gene expression.

(-)-Epicatechin, at concentrations $>30 \mu \mathrm{m}$, exhibits vasodilator effects in vitro, which are partially endothelium- and NOdependent ${ }^{(14,15)}$. (-)-Epicatechin activates eNOS in human coronary artery endothelial cells by (i) Ser-633 and Ser-1170 phosphorylation and Thr-495 dephosphorylation, and (ii) via $\mathrm{Ca}^{2+} /$ calmodulin-dependent kinase II pathways, leading to increased NO production ${ }^{(17)}$. Moreover, (-)-epicatechin and its two in situ O-methylated metabolites elevate NO in endothelial cells via inhibition of NADPH oxidase ${ }^{(18)}$. However, it is predictable that this acute effect was absent in vivo in animals 

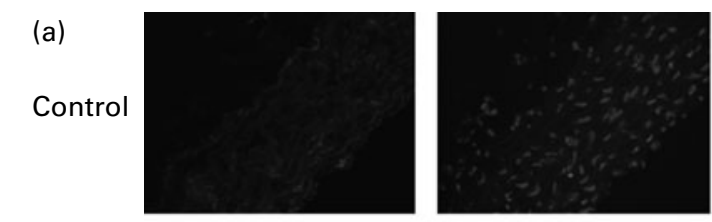

(b)
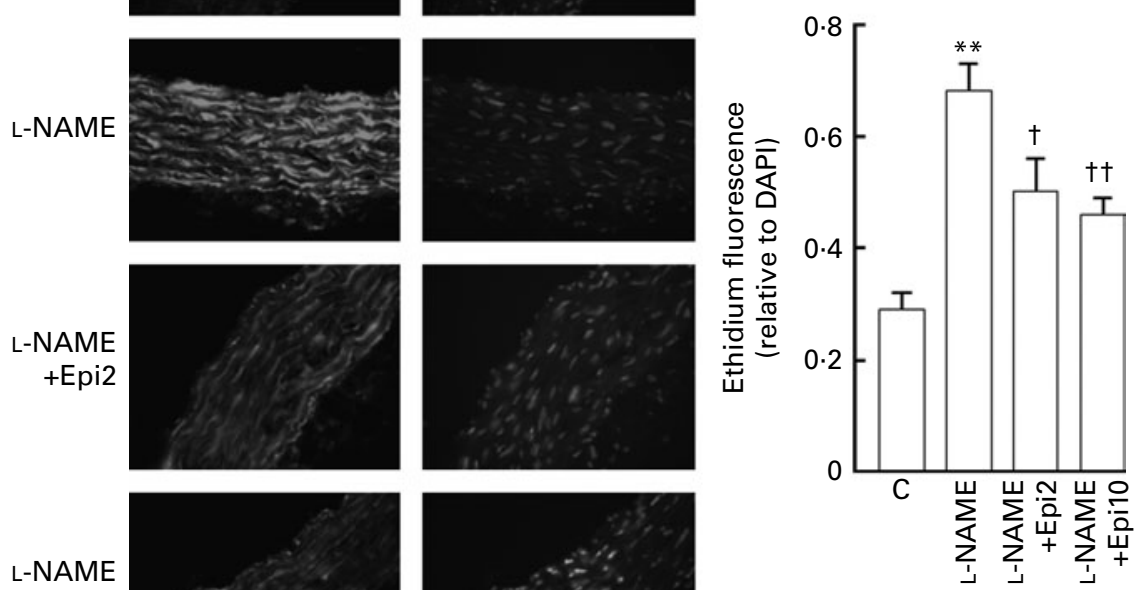

L-NAME

+ Epi10
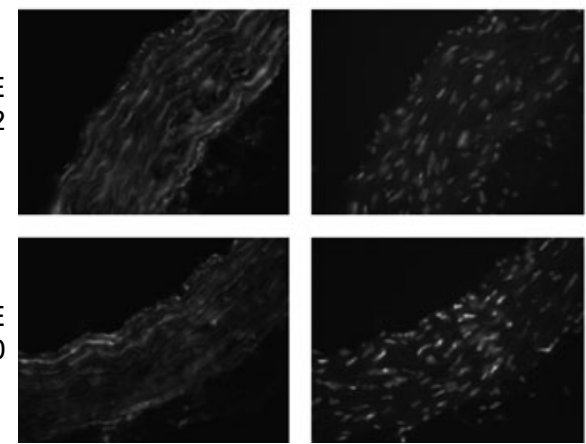

Fig. 7. Effects of epicatechin (Epi) in aortic superoxide anion $\left(\mathrm{O}_{2}^{-}\right)$levels. (a) Left pictures show arteries incubated in the presence of dihydroethidium which produces a red fluorescence when oxidised to ethidium by $\mathrm{O}_{2}^{-}$. Right pictures show blue fluorescence of the nuclear stain $4^{\prime}-6$-diamidino-2-phenylindole (DAPI) $(400 \times$ magnification). (b) Averaged values, mean with their standard errors ( $n$ 5-7 rings from different rats) of the red ethidium fluorescence normalised to the blue DAPI fluorescence in aortae from control (C), $N^{G}$-nitro-L-arginine methyl ester (L-NAME), L-NAME $+2 \mathrm{mg} / \mathrm{kg}$ Epi (Epi 2) and L-NAME + 10 mg/kg Epi (Epi 10) groups. Values are means, with their standard errors represented by vertical bars. ${ }^{*}$ Mean values were significantly different between the L-NAME and $\mathrm{C}$ groups $(P<0.01)$. Mean values were significantly different between the L-NAME-Epi and L-NAME groups: $\dagger P<0.05 ; \dagger+P<0.01$.

treated with L-NAME because: (1) the concentrations of $(-)$ epicatechin in plasma after 2 or $10 \mathrm{mg} / \mathrm{kg}(-)$-epicatechin ${ }^{(26)}$ are below its active range of concentrations as vasodilators and (2) its relaxant response would be small under conditions of inhibited eNOS. Therefore, the lack of antihypertensive effect of (-)-epicatechin in this model of hypertension may be related, at least in part, to the absence of acute vasodilator effect.

\section{Renal and cardiac injury}

Renal injury has been consistently reported after chronic inhibition of NO synthesis ${ }^{(20)}$. In our study, the L-NAME group presented moderate/severe kidney injury, especially in the vasculature, and with low tubular casts and mild tubular atrophy. The main and most intense vascular lesion in L-NAME rats was hyaline arteriopathy and thickening of vascular wall (proliferative arteriopathy) with moderate decrease of lumen, which was observed almost always in medium-sized vessels. These histological findings were associated with proteinuria, indicating functional impairment of the glomerular wall barrier. (-)-Epicatechin, at the higher dose used, partially prevented renal parenchyma and vascular lesions and proteinuria, indicating that (-)-epicatechin protects, at least partially, from L-NAME-induced renal injury, despite the lack of antihypertensive effect. A modest left ventricular hypertrophy has also been found in this model of hypertension ${ }^{(27)}$. In our study, the heart and left ventricular weight indices were significantly increased in L-NAME-treated rats and these effects were significantly prevented by $10 \mathrm{mg} / \mathrm{kg}(-)$-epicatechin. These protective effects would be at least partly due to a reduction in ROS and proinflammatory cytokines induced by (-)-epicatechin, which are potent stimulus for cardiac growth and renal injury ${ }^{(28,29)}$.

\section{Endothelial dysfunction, NO and cyclo-oxygenase-derived vasoconstrictors}

Administration of L-NAME is associated with endothelial dysfunction $^{(20)}$. As expected, L-NAME-treated rats showed reduced endothelium-dependent vasodilator responses induced by acetylcholine in both small arteries and in aorta, with similar endothelium-independent relaxant response to the NO donor nitroprusside. (-)-Epicatechin $10 \mathrm{mg} / \mathrm{kg}$ only weakly prevented this effect in both vascular beds, without affecting NO sensitivity, since it did not modify the vasodilation induced by nitroprusside.

L-NAME inhibits the constitutive $\mathrm{Ca}^{2+}$-dependent NOS isoforms (eNOS and nNOS) and the $\mathrm{Ca}^{2+}$-independent inducible NOS isoform. However, these inhibitory effects on NOS activity were associated with increased eNOS expression in aortic tissues, which may be viewed as a compensatory mechanism to maintain the production of bioactive NO in the face of increased oxidant stress ${ }^{(30)}$. (-)-Epicatechin reduced eNOS gene and protein overexpression, possibly as a result of the reduced vascular superoxide levels in the aortae. Interestingly, 
(b)
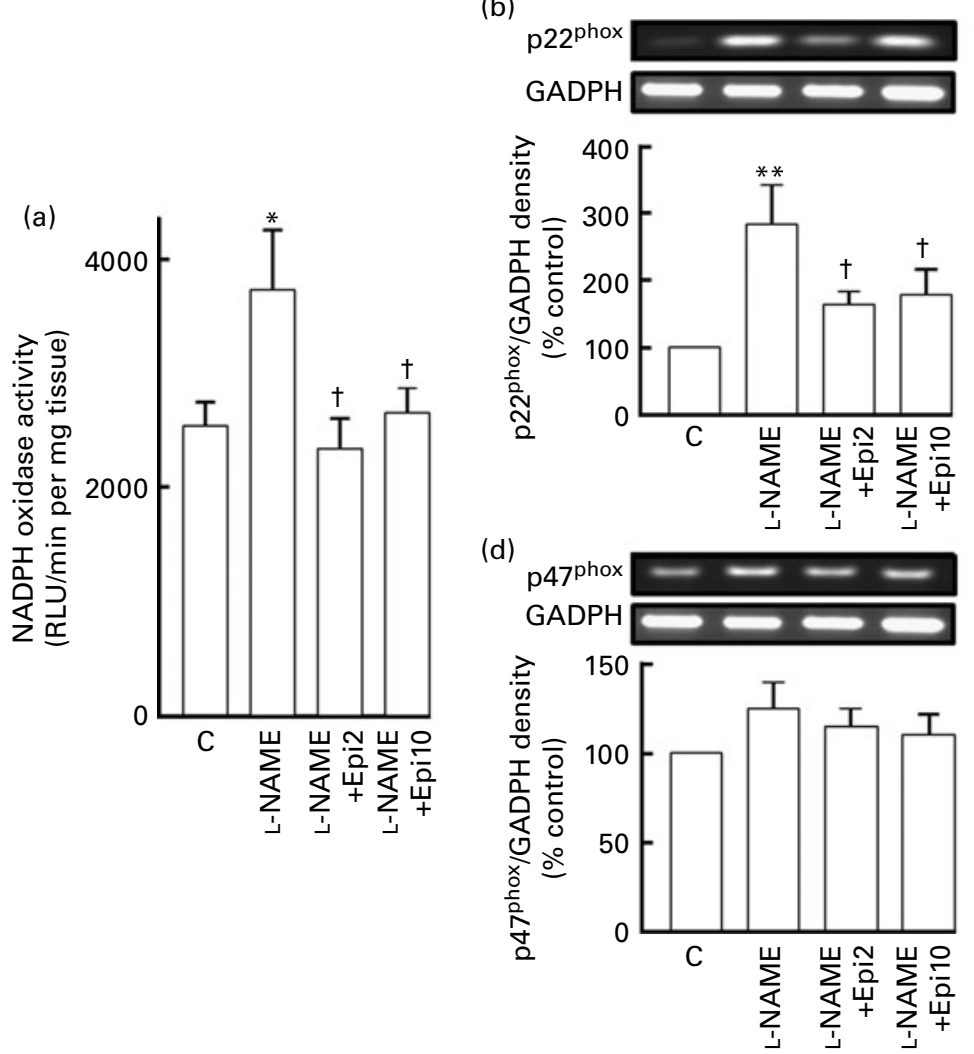

(c)
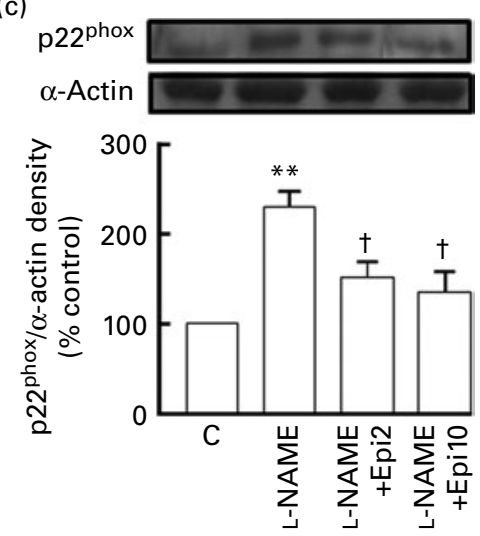

(e) $p 47^{\text {phox }}$

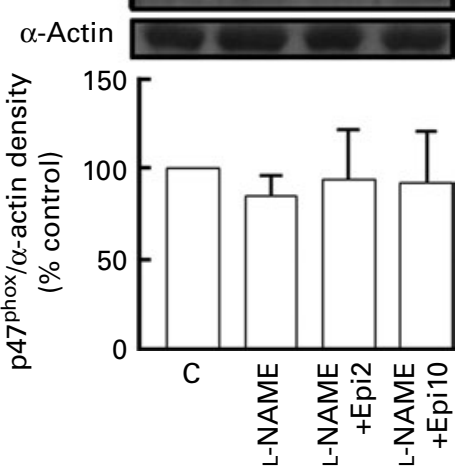

Fig. 8. Effects of epicatechin (Epi) in the NADPH oxidase pathway. (a) NADPH oxidase activity measured by lucigenin-enhanced chemiluminescence, and expression of NADPH oxidase subunits $p 22^{\text {phox }}$ and p $47^{\text {phox }}$ at the level of ( $b$ and d) mRNA by RT-PCR and (c and e) protein by Western blot in aortae from control (C), $N^{G}$-nitro-L-arginine methyl ester (L-NAME), L-NAME $+2 \mathrm{mg} / \mathrm{kg} \mathrm{Epi} \mathrm{(Epi} \mathrm{2)} \mathrm{and} \mathrm{L-NAME}+10 \mathrm{mg} / \mathrm{kg}$ Epi (Epi 10) groups. Panels show representative bands and histograms represent densitometric values normalised to the corresponding RT-PCR products of $(b$ and d) glyceraldehyde 3-phosphate dehydrogenase (GADPH) or normalised to the corresponding (c and e) $\alpha$-actin. Values are means, with their standard errors represented by vertical bars $(n)-5)$. Mean values were significantly different between the L-NAME and C groups: ${ }^{\star} P<0.05$, ${ }^{\star \star} P<0.01$. † Mean values were significantly different between the L-NAME-Epi and L-NAME groups $(P<0 \cdot 05)$. RLU, relative luminescence units.

we also found an increased eNOS phosphorylation of Ser1177, associated with an increased vascular Akt phosphorylation in both groups of rats treated with (-)-epicatechin. These in vivo results are consistent with previous in vitro observations showing (-)-epicatechin-induced eNOS activation via PI3K/Akt-mediated phosphorylation in human endothelial cells ${ }^{(17)}$.

In addition, increased endothelium-dependent vasoconstriction induced by acetylcholine in the presence of L-NAME in the organ chamber was also observed in aorta from L-NAME-treated rats. These contractions have been previously attributed to increased endothelial release of COX-derived vasoconstrictor prostanoids (such as PGH2 or thromboxane $\left.\mathrm{A}_{2}\right)^{(31,32)}$. Likewise, COX-2 overexpression was found in aorta from L-NAME-treated rats. (-)-Epicatechin at $10 \mathrm{mg} / \mathrm{kg}$ reduced acetylcholine-induced vasoconstriction and prevented the increase in COX-2, suggesting that (-)-epicatechin inhibits the release of COX-derived metabolites by down-regulating COX-2. Thus, although chronic (-)-epicatechin prevented the secondary changes in endothelial function (due to increased release of endothelial vasoconstrictors), it was unable to restore the primary endothelial defect (i.e. deficient NO production).

\section{Systemic and vascular reactive oxygen species and inflammatory markers}

ROS have been suggested to contribute to the genesis of atherosclerosis, diabetes, IHD, heart failure and hypertension. The L-NAME model of hypertension has been also associated with increased systemic oxidative stress ${ }^{(32)}$. In fact, plasma MDA values which reflect a general index of the oxidative status and lipid peroxidation and the $24 \mathrm{~h}$ urinary levels of isoprostane $\mathrm{F}_{2 \alpha}$, a PG-like compound produced by the reaction of arachidonic acid and superoxide ${ }^{(33)}$, were increased in the present study. (-)-Epicatechin in vitro is known to possess antioxidant properties ${ }^{(34)}$ and reduces the MDA content in erythrocytes from hypertensive patients ${ }^{(35)}$. In agreement with these data, in our experiment, long-term (-)-epicatechin treatment reduced plasma MDA levels and the urinary levels of isoprostanes.

In agreement with other models of hypertension ${ }^{(36)}$, hypertension induced by chronic blockade of NO production was associated with an overproduction of ROS also within the arterial wall ${ }^{(37)}$. In our in situ detection of $\mathrm{O}_{2}^{-}$production study, we found that rings from the L-NAME group showed marked staining as compared to control rats, and it was distributed in all layers of the aortic wall. This overproduction 
(a)

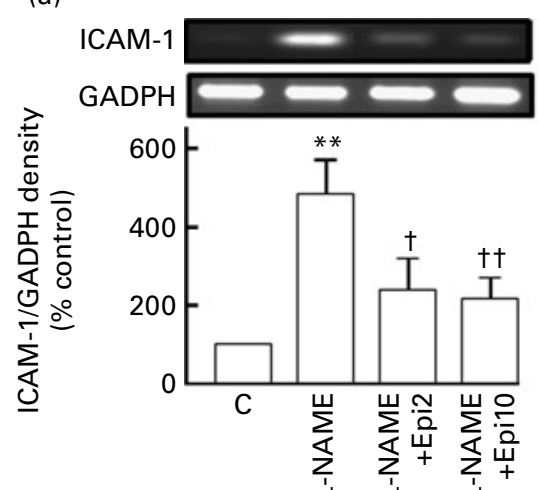

(c)

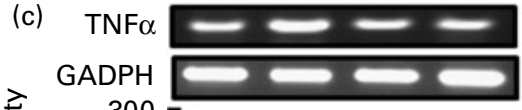

(b)

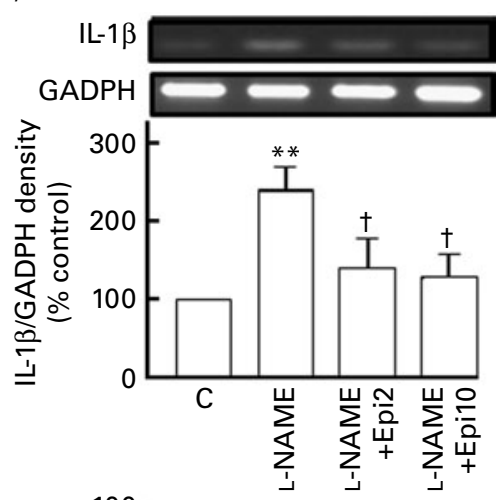

(d)

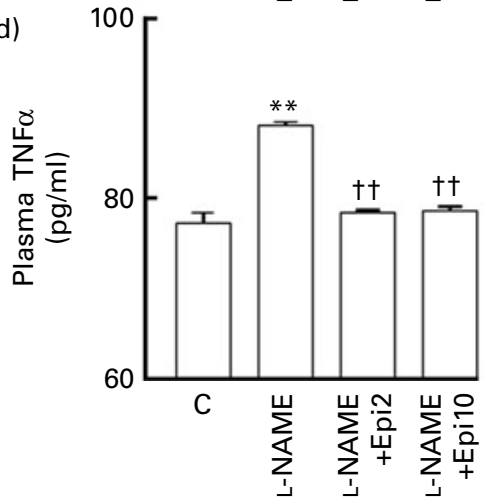

Fig. 9. Effects of epicatechin (Epi) in proinflammatory genes. Panels show representative bands and histograms represent densitometric values normalised to the corresponding RT-PCR products of (a) glyceraldehyde 3-phosphate dehydrogenase (GADPH) for intercellular adhesion molecule-1 (ICAM-1), (b) IL-1 I $\beta$ and (c) $\mathrm{TNF} \alpha(n 3-5)$ in aortae from control (C), $N^{\mathrm{G}}$-nitro-L-arginine methyl ester (L-NAME), L-NAME $+2 \mathrm{mg} / \mathrm{kg}$ Epi (Epi 2) and L-NAME $+10 \mathrm{mg} / \mathrm{kg}$ Epi (Epi 10$)$ groups. (d) Plasma TNF $\alpha$ levels in all experimental groups. Values are means, with their standard errors represented by vertical bars. ${ }^{* *}$ Mean values were significantly different between the L-NAME and C groups $(P<0.01)$. Mean values were significantly different between the L-NAME-Epi and L-NAME groups: $† P<0.05, \dagger \dagger P<0.01$.

may be due, at least in part, to an increase in NADPH oxidase activity, as suggested by both NADPH-stimulated lucigenin-enhanced chemiluminescence and an increase in $\mathrm{p} 22^{\text {phox }}$ expression (present results and Gonzalez et al. ${ }^{(37)}$ ).
(-)-Epicatechin, at both doses, strongly reduced ethidium fluorescence, NADPH oxidase activity and $\mathrm{p} 22^{\text {phox }}$ up-regulation in aortic rings from L-NAME-treated rats. Similar results in the vascular wall were also described using a higher dose (a)
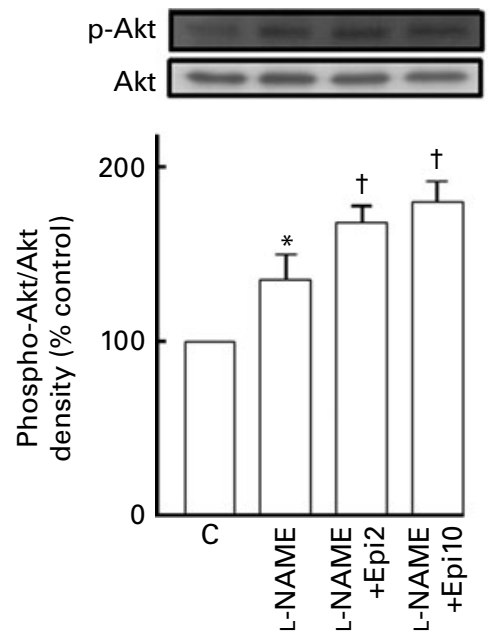

(b)
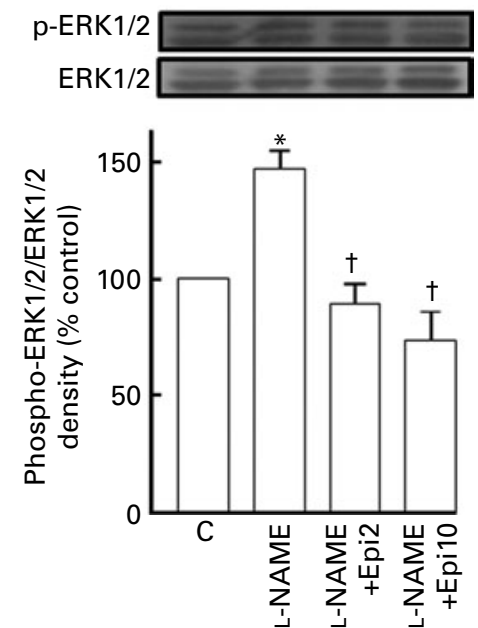

Fig. 10. Effects of epicatechin (Epi) in protein kinase B (Akt) and extracellular-signal-regulated kinase (ERK) pathways. (a and b) Representative bands and histograms represent densitometric values of phospho-Akt and phospho-ERK1/2 (p-ERK1/2) relative to total Akt and ERK1/2 protein levels ( $n 3-5)$ in aortae from control (C), $N^{G}$-nitro-L-arginine methyl ester (L-NAME), L-NAME $+2 \mathrm{mg} / \mathrm{kg}$ Epi (Epi 2) and L-NAME $+10 \mathrm{mg} / \mathrm{kg}$ Epi (Epi 10) groups. Values are means, with their standard errors represented by vertical bars. ${ }^{*}$ Mean values were significantly different between the L-NAME and $\mathrm{C}$ groups $(P<0 \cdot 05)$. $†$ Mean values were significantly different between the L-NAME-Epi and L-NAME groups $(P<0.05)$. 


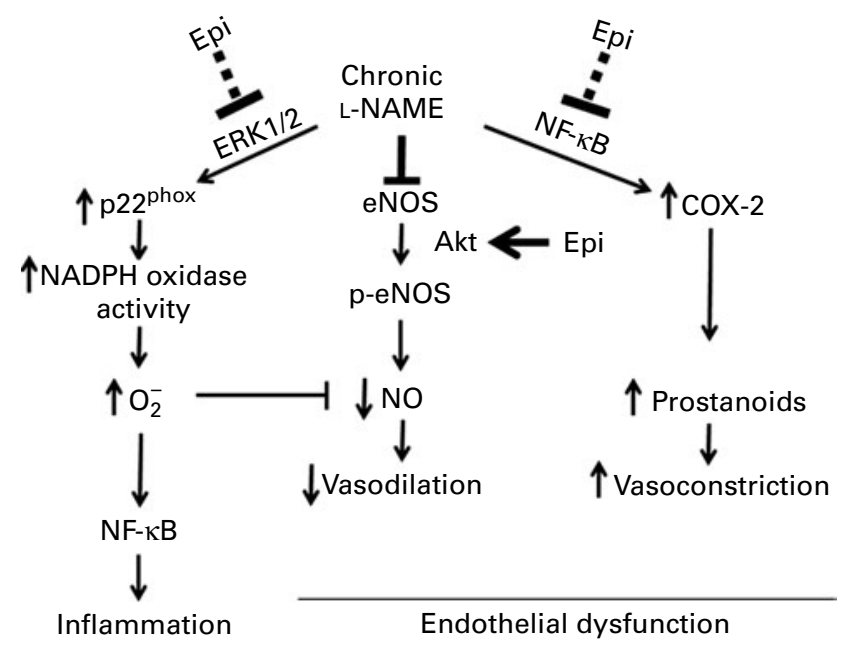

Fig. 11. Schematic diagram representing the mechanism of action of epicatechin (Epi) on the inflammatory and vascular dysfunction pathways in nitric oxide (NO)-deficient hypertensive rats. L-NAME, $N^{G}$-nitro-L-arginine methyl ester; eNOS, endothelial NO synthase; p-eNOS, phospho-eNOS; COX-2, cyclo-oxygenase $2 ; \mathrm{O}_{2}^{-}$, superoxide anion; ERK1/2, extracellular-signal-regulated kinase $1 / 2$.

$(30 \mathrm{mg} / \mathrm{kg})$ of its stereoisomer catechin in prediabetic Otsuka Long Evans Tokushima Fatty rats ${ }^{(16)}$. In our study, chronic NO inhibition also induced increased ERK1/2 phosphorylation, an effect which was prevented by (-)-epicatechin and may be involved in its inhibitory effects on NADPH oxidase activity.

Monocyte recruitment is one of the early steps in hypertension-induced arteriosclerosis and perivascular fibrosis ${ }^{(38)}$. Chronic NO suppression induced an increase in ex vivo monocyte endoluminal adhesion and in in vivo perivascular macrophage accumulation, in concert with increases in oxidative stress and inflammatory cytokines in the arterial wall $^{(19)}$. IL-1 $\beta$, ICAM- 1 and TNF $\alpha$ mRNA levels were increased in the vascular wall of the L-NAME-treated rats, suggesting that proinflammatory signals come from the arterial wall. The expression of adhesion molecules and proinflammatory cytokines are mainly the products of inducible genes that are usually controlled, at least in part, by the redox-sensitive NF-кB pathway ${ }^{(39)}$. The increase in oxidative stress in the vascular wall of L-NAME-treated rats probably activates the NF-кB system, which, in turn, induces the expression of proinflammatory cytokines ${ }^{(40)}$. Our results further support this hypothesis, since (-)-epicatechin, which reduced aortic superoxide levels also inhibited the vascular expression of these proinflammatory and proatherogenic markers.

In the present model in which NO bioactivity is impaired, no change in blood pressure and only marginal effects on endothelial function were found with (-)-epicatechin. This contrasts with human intervention studies with tea ${ }^{(1)}$ and with the effects of epicatechin in other animal models of hypertension (M Gomez-Guzman, R Jimenez and J Duarte, unpublished results) indicating that NO plays an essential role in the effects of (-)-epicatechin on blood pressure and endothelial function. Our results are consistent with favourable effects of tea and other flavanol-containing food on cardiovascular risk factors ${ }^{(5)}$. However, caution should be taken with the potential use of green tea extracts as supplements, rich in (-)-epicatechin, because of reports of potential liver damage at high doses.

In conclusion, the present study demonstrates that chronic (-)-epicatechin treatment, at doses equivalent to those that can be achieved in the human diet, prevented cardiac hypertrophy, renal parenchyma and vascular lesions and proteinuria, and blunted the prostanoid-mediated enhanced endothelium-dependent vasoconstrictor responses in the model of chronic inhibition of NO synthesis with L-NAME. Furthermore, (-)-epicatechin also reduced the vascular oxidative stress and proinflammatory status, early events involved in atherosclerosis development.

\section{Acknowledgements}

The present study was supported by Grants from Comisión Interministerial de Ciencia y Tecnología (AGL2007-66108/ ALI, SAF2007-62731, SAF2008-03948, SAF2010-22066-C02-01), from Junta de Andalucía, Proyecto de Excelencia (P06-CTS01555) and by the Ministerio de Ciencia e Innovación, Instituto de Salud Carlos III (Red HERACLES RD06/0009), Spain. M. J. Z., P. G., M. R., R. L.-S., A. M. Q., M. G.-G. and E. B. are holders of studentships from Spanish Ministry of Science and Education. The authors declare no conflicts of interest. J. D. and R. J. designed the experiments, J. D. and F. P.-V. wrote the manuscript, and all others performed and analysed the experiments and contributed to the discussion.

\section{References}

1. Duffy SJ, Keaney JF Jr JF, Holbrook M, et al. (2001) Shortand long-term black tea consumption reverses endothelial dysfunction in patients with coronary artery disease. Circulation 104, 151-156.

2. Buijsse B, Feskens EJ, Kok FJ, et al. (2006) Cocoa intake, blood pressure, and cardiovascular mortality: the Zutphen Elderly Study. Arch Intern Med 166, 411-417.

3. Ding EL, Hutfless SM, Ding X, et al. (2006) Chocolate and prevention of cardiovascular disease: a systematic review. Nutr Metab (Lond) 3, 2.

4. Nagao T, Hase T \& Tokimitsu I (2007) A green tea extract high in catechins reduces body fat and cardiovascular risks in humans. Obesity (Silver Spring) 15, 1473-1483.

5. Deka A \& Vita JA (2011) Tea and cardiovascular disease. Pharmacol Res 64, 136-145.

6. Fisher ND, Hughes M, Gerhard-Herman M, et al. (2003) Flavanol-rich cocoa induces nitric-oxide-dependent vasodilation in healthy humans. J Hypertens 21, 2281-2286.

7. Hirata K, Shimada K, Watanabe H, et al. (2004) Black tea increases coronary flow velocity reserve in healthy male subjects. Am J Cardiol 93, 1384-1388, A1386.

8. Schroeter H, Heiss C, Balzer J, et al. (2006) (-)-Epicatechin mediates beneficial effects of flavanol-rich cocoa on vascular function in humans. Proc Natl Acad Sci U S A $\mathbf{1 0 3}$ 1024-1029.

9. Taubert D, Berkels R, Roesen R, et al. (2003) Chocolate and blood pressure in elderly individuals with isolated systolic hypertension. JAMA 290, 1029-1030.

10. Matsuyama T, Tanaka Y, Kamimaki I, et al. (2008) Catechin safely improved higher levels of fatness, blood pressure, 
and cholesterol in children. Obesity (Silver Spring) $\mathbf{1 6}$, 1338-1348.

11. Grassi D, Lippi C, Necozione S, et al. (2005) Short-term administration of dark chocolate is followed by a significant increase in insulin sensitivity and a decrease in blood pressure in healthy persons. Am J Clin Nutr 81, 611-614.

12. Holt RR, Lazarus SA, Sullards MC, et al. (2002) Procyanidin dimer $\mathrm{B}_{2}$ [epicatechin-(4beta-8)-epicatechin] in human plasma after the consumption of a flavanol-rich cocoa. $\mathrm{Am} \mathrm{J}$ Clin Nutr 76, 798-804.

13. Keen CL, Holt RR, Oteiza PI, et al. (2005) Cocoa antioxidants and cardiovascular health. Am J Clin Nutr 81, 298S-303S.

14. Duarte J, Perez Vizcaino F, Utrilla P, et al. (1993) Vasodilatory effects of flavonoids in rat aortic smooth muscle. Structureactivity relationships. Gen Pharmacol 24, 857-862.

15. Huang Y, Zhang A, Lau CW, et al. (1998) Vasorelaxant effects of purified green tea epicatechin derivatives in rat mesenteric artery. Life Sci 63, 275-283.

16. Ihm SH, Lee JO, Kim SJ, et al. (2009) Catechin prevents endothelial dysfunction in the prediabetic stage of OLETF rats by reducing vascular NADPH oxidase activity and expression. Atherosclerosis 206, 47-53.

17. Ramirez-Sanchez I, Maya L, Ceballos G, et al. (2010) (-)Epicatechin activation of endothelial cell endothelial nitric oxide synthase, nitric oxide, and related signaling pathways. Hypertension 55, 1398-1405.

18. Steffen Y, Gruber C, Schewe T, et al. (2008) Mono-Omethylated flavanols and other flavonoids as inhibitors of endothelial NADPH oxidase. Arch Biochem Biophys 469, 209-219.

19. Luvara G, Pueyo ME, Philippe M, et al. (1998) Chronic blockade of NO synthase activity induces a proinflammatory phenotype in the arterial wall: prevention by angiotensin II antagonism. Arterioscler Thromb Vasc Biol 18, 1408-1416.

20. Zatz R \& Baylis C (1998) Chronic nitric oxide inhibition model six years on. Hypertension 32, 958-964.

21. Duarte J, Perez-Palencia R, Vargas F, et al. (2001) Antihypertensive effects of the flavonoid quercetin in spontaneously hypertensive rats. BrJ Pharmacol 133, 117-124.

22. Esterbauer H \& Cheeseman KH (1990) Determination of aldehydic lipid peroxidation products: malonaldehyde and 4-hydroxynonenal. Methods Enzymol 186, 407-421.

23. Duarte J, Ocete MA, Perez-Vizcaino F, et al. (1997) Effect of tyrosine kinase and tyrosine phosphatase inhibitors on aortic contraction and induction of nitric oxide synthase. Eur $J$ Pharmacol 338, 25-33.

24. Vera R, Sanchez M, Galisteo M, et al. (2007) Chronic administration of genistein improves endothelial dysfunction in spontaneously hypertensive rats: involvement of eNOS, caveolin and calmodulin expression and NADPH oxidase activity. Clin Sci (Lond) 112, 183-191.

25. Sanchez M, Lodi F, Vera R, et al. (2007) Quercetin and isorhamnetin prevent endothelial dysfunction, superoxide production, and overexpression of $\mathrm{p} 47 \mathrm{phox}$ induced by angiotensin II in rat aorta. J Nutr 137, 910-915.

26. Piskula MK \& Terao J (1998) Accumulation of (-)-epicatechin metabolites in rat plasma after oral administration and distribution of conjugation enzymes in rat tissues. $J$ Nutr 128, 1172-1178.

27. Bartunek J, Weinberg EO, Tajima M, et al. (2000) Chronic $N(G)$-nitro-L-arginine methyl ester-induced hypertension: novel molecular adaptation to systolic load in absence of hypertrophy. Circulation 101, 423-429.

28. Li JM, Gall NP, Grieve DJ, et al. (2002) Activation of NADPH oxidase during progression of cardiac hypertrophy to failure. Hypertension 40, 477-484.

29. Vaziri ND (2004) Roles of oxidative stress and antioxidant therapy in chronic kidney disease and hypertension. Curr Opin Nephrol Hypertens 13, 93-99.

30. Zhen J, Lu H, Wang XQ, et al. (2008) Upregulation of endothelial and inducible nitric oxide synthase expression by reactive oxygen species. Am J Hypertens 21, 28-34.

31. Auch-Schwelk W, Katusic ZS \& Vanhoutte PM (1990) Thromboxane $\mathrm{A}_{2}$ receptor antagonists inhibit endotheliumdependent contractions. Hypertension 15, 699-703.

32. Duarte J, Jimenez R, O'Valle F, et al. (2002) Protective effects of the flavonoid quercetin in chronic nitric oxide deficient rats. J Hypertens 20, 1843-1854.

33. Belik J, Gonzalez-Luis GE, Perez-Vizcaino F, et al. (2010) Isoprostanes in fetal and neonatal health and disease. Free Radic Biol Med 48, 177-188.

34. van Acker SA, van den Berg DJ, Tromp MN, et al. (1996) Structural aspects of antioxidant activity of flavonoids. Free Radic Biol Med 20, 331-342.

35. Kumar N, Kant R \& Maurya PK (2010) Concentrationdependent effect of (-)-epicatechin in hypertensive patients. Phytother Res 24, 1433-1436.

36. Sanchez M, Galisteo M, Vera R, et al. (2006) Quercetin downregulates NADPH oxidase, increases eNOS activity and prevents endothelial dysfunction in spontaneously hypertensive rats. $J$ Hypertens 24, 75-84.

37. Gonzalez W, Fontaine V, Pueyo ME, et al. (2000) Molecular plasticity of vascular wall during $N(G)$-nitro-L-arginine methyl ester-induced hypertension: modulation of proinflammatory signals. Hypertension 36, 103-109.

38. Nicoletti A \& Michel JB (1999) Cardiac fibrosis and inflammation: interaction with hemodynamic and hormonal factors. Cardiovasc Res $\mathbf{4 1}, 532-543$.

39. Brand K, Page S, Walli AK, et al. (1997) Role of nuclear factor-kappa B in atherogenesis. Exp Physiol 82, 297-304.

40. Hernandez-Presa M, Bustos C, Ortego M, et al. (1997) Angiotensin-converting enzyme inhibition prevents arterial nuclear factor-kappa B activation, monocyte chemoattractant protein-1 expression, and macrophage infiltration in a rabbit model of early accelerated atherosclerosis. Circulation 95 , $1532-1541$. 